\title{
Tramas cruzadas en el extraño caso de Juan Luis Martínez*
}

\section{Crossed Plots in the Strange Case of Juan Luis Martínez}

Arturo Gutiérrez Plaza ${ }^{\text {a }}$

DOI: https://doi.org/10.11144/Javeriana.cl25.tcec

Universidad Simón Bolivar, Venezuela

arturogutierrezplaza@gmail.com

ORCID: https://orcid.org/0000-0002-9668-0834

Recibido: 15 Mayo 2020

Aceptado: 14 Agosto 2020

Publicado: 20 Agosto 2021

\section{Resumen:}

En este artículo se hace una revisión de algunas tramas cruzadas en la obra de Juan Luis Martínez, particularmente en La nueva novela, relativas específicamente a 1) sus modos de inserción en el campo poético chileno, considerando especialmente las formas en las que se relacionan con las obras de Vicente Huidobro y la Nicanor Parra, que anteceden su obra; 2) sus estrategias de simulación, parodia y ocultamiento de la figura y de la identidad del autor, así como su paradójica vinculación con el legado borgiano; 3) las convergencias y divergencias entre el pensamiento oriental y occidental o la asunción de la imposibilidad del poema: el pajarístico atrapado en la red del ideograma.

Palabras clave: poesía chilena, Juan Luis Martínez, neovanguardia, La nueva novela, arte visual.

\begin{abstract}
:
This article reviews certain crossed plots in the work of Juan Luis Martínez, particularly in La nueva novela, specifically related to 1) their modes of insertion into the field of Chilean poetry, especially considering the way they relate to the works of Vicente Huidobro and Nicanor Parra, that precede its work; 2) their strategies of simulation, parody, and shrouding of the figure and identity of the author, as well as their paradoxical connection to the legacy of Borges; 3 ) the convergences and divergences between Eastern and Western thought, or the assumption of the impossibility of the poem: the "pajarístico" trapped in the net of the ideogram.
\end{abstract}

Keywords: Chilean poetry, Juan Luis Martínez, neo avant-garde, La nueva novela, visual art.

\section{Noticias del extranjero}

Quisiera comenzar estas palabras expresando lo que ellas desean ser: un modesto homenaje a un ser apasionado por todo lo literario, apasionado pero apolíneo, mesurado, un hombre generoso, sabio y humilde, un notable poeta, ensayista y profesor chileno, un verdadero hiperlector, como lo calificara Enrique Lihn, que se ha empeñado a lo largo de su vida en llevar noticias sobre la literatura escrita en nuestra América a las distintas comarcas que conforman este continente. Un hombre cuya secreta misión ha sido la de enseñarnos una lección, también por él aprendida de maestros como el chileno Ricardo Latcham (1903-1965), el argentino Ezequiel Martínez Estrada (1895-1964) y el venezolano Mariano Picón Salas (1901-1965) — quien vivió, estudió y trabajo en Chile entre 1922 y 1936- y que consiste en recordarnos que no somos una suma de ínsulas extrañas, sino un continente enlazado por una historia, una lengua, una geografía y una cultura común. Estas palabras se las dedico a Pedro Lastra (1932), gracias a quien tuve, en Caracas, las primeras noticias de la obra del poeta y artista chileno Juan Luis Martínez (1942-1993).

Fue en el año 1998, en una conferencia titulada "Sobre poetas marginales" — dictada en el Centro de Estudios Latinoamericanos Rómulo Gallegos y publicada ese mismo año en la revista Mapocho-, que Pedro Lastra nos proveyó las primeras "señales de ruta" para acceder a la obra de Martínez. El caso de este poeta, sin duda singular no solo en Chile, sino en toda Hispanoamérica, lo trataba junto con el de otros poetas y escritores latinoamericanos, entre los que se cuentan, en un breve recuento histórico, figuras como:

Notas de autor

a Autor de correspondencia. Correo electrónico: arturogutierrezplaza@gmail.com 
Felisberto Hernández (1902-1964) y Líber Falco (1906-1955), en Uruguay; Pablo Palacio (1906-1947), en Ecuador; José María Eguren (1874-1942) y Martín Adán (1908-1985), en Perú; José Antonio Ramos Sucre (1890-1930), en Venezuela; Aurelio Arturo (1906-1974), en Colombia; Jaime Sáenz (1921-1986), en Bolivia; Gastón Baquero (1914-1997), en Cuba; o Alberto Rojas Jiménez (1900-1934), Omar Cáceres (1904-1943), Juan Emar (1893-1964), María Luisa Bombal (1910-1980) y Eduardo Anguita (1914-1992), en Chile, entre otros.

Tras esas "noticias del extranjero" - y hago uso de esta expresión que juega con la doble acepción de la palabra extranjero, en correspondencia con este homenaje al maestro Lastra, pues ese es el ingenioso y pertinente título de uno de sus varios libros de poesía-, unos cuantos comenzamos a leer y distribuir con entusiasmo, en Venezuela, algunos de los extraordinarios poemas de Martínez. Así, se fue conformando una pequeña, muy pequeña pero animada, secta de seguidores del autor de La nueva novela, aun cuando nunca habíamos visto ejemplares de sus obras. Recuerdo, incluso, una ocasión posterior en la que el mismo Lastra me hizo llegar fotocopias de algunos poemas de Martínez (entre ellos: "La probable e improbable desaparición de un gato por extravío de su propia porcelana", "La desaparición de una familia” y "Observaciones relacionadas con la exuberante actividad de la 'confabulación fonética' o 'lenguaje de los pájaros' en las obras de J. P. Brisset, R. Roussel, M. Duchamp y otros") para entregárselos al poeta venezolano Rafael Cadenas (1930), recientemente honrado con el Premio Iberoamericano de Poesía "Reina Sofía", quien le había manifestado en una conversación caraqueña su interés por conocer más de la obra de ese autor. Desde hace tiempo, otros amigos, como el chileno Marcelo Rioseco (1967) y el venezolano Luis Miguel Isava (1958), han sido interlocutores frecuentes interesados también en el seguimiento de las huellas de este creador. A estas alturas, aunque aún está lejos de ser un caso de la poesía hispanoamericana suficientemente conocido más allá de las fronteras chilenas, sí se puede constatar, al hacer el recuento de los trabajos críticos que en los últimos años se han producido, la progresiva proyección e interés que en diferentes latitudes ha ido adquiriendo la apuesta creativa de Martínez.

\section{El triángulo equilátero, la teatralidad de un yo desdoblado por la fortuna}

Dicho esto, intentemos adentrarnos en la exposición de lo que podríamos denominar como la presencia de tramas cruzadas dentro la obra de Juan Luis Martínez, particularmente en su libro-objeto La nueva novela, publicado en 1977. Trataremos de explorar, entre otras cosas y a grosso modo, cómo, a través de ciertas relaciones binomiales, se confecciona y caracteriza en La nueva novela un sistema de oposiciones, muchas veces complementarias, desde las que se tejen dichas tramas que, al tiempo que estimulan en el lector la búsqueda de claves para alcanzar cierta coherencia interpretativa, le advierten sobre la inutilidad de toda pretensión hermenéutica, dado el carácter idealista e ilusorio, ciertamente lúdico, de la relación entre significantes y virtuales significados. Digamos que entre las tareas que se propone esa obra está la de crear un lector-observador, condenado al asedio perceptivo de encontrarse in aeternumbajo un continuo e insoluble descolocamiento, descentramiento, desplazamiento. Una marcada proliferación de núcleos binomiales va informando al lector sobre la dinámica de este sistema a medida que desplaza su mirada sobre las páginas de esta obra. En las siguientes líneas, nos ocuparemos de algunas de las tramas tensadas desde tales polaridades. Detengámonos antes, sin embargo, un momento, en la consideración del campo literario en el que tiene lugar la propuesta artística de Juan Luis Martínez.

Comencemos por una observación de Guillermo Sucre (1936), un valioso crítico y poeta venezolano, quien también vivió varios años de su juventud en Chile y es el autor de un libro fundamental y ya canónico dentro de los estudios de la poesía hispanoamericana llamado La máscara, la transparencia -el cual fue originalmente publicado en Monte Ávila en 1975 y cuenta con posteriores ediciones en el Fondo de Cultura Económica y con una más reciente publicada en la editorial El Estilete, de Caracas, en el 2016-. Según observa Sucre 
de modo sucinto en una entrevista titulada "Diálogos a la distancia", hecha por Ioannis Antzus Ramos y publicada en la revista digital Trópico Absoluto, desde su punto de vista, en un importante segmento de la tradición poética chilena "el vínculo entre poesía y vida se convierte en apoteosis o teatralidad del yo". Este comentario que señala un rasgo tal vez parcial, pero, sin duda, característico y diferencial con respecto a otras tradiciones poéticas hispanoamericanas en las que la llamada guerrilla literaria es mucho más atenuada, podría servirnos para iniciar una aproximación al asunto del yo en la obra de Juan Luis Martínez, así como para identificar su estrategia de inserción en el campo poético chileno.

Remitámonos a los orígenes de la vanguardia literaria hispanoamericana. Fue Vicente Huidobro (1893-1948) el primero en aludir, dentro de un poema vinculado a su propio nombre y enmascarado a su vez tras la etiqueta de antipoeta como gesto autorreferencial mediante la voz de su alter ego Altazor, a la pregunta: “QQué has hecho de mí Vicente Huidobro?”; calificándose pocos versos después, en el mismo canto, como un "ángel salvaje" y "Poeta/Anti poeta/Culto/Anti culto". En las medianías del siglo XX, Nicanor Parra (1914-2018) retomará el término, desde distintos ámbitos ideológicos y estéticos, como promotor de los postulados de una poesía conversacional bajada del Olimpo y, por ende, desentendida de las alturas altazorianas y de "La poesía de pequeño Dios", como la identificara en su célebre "Manifiesto", pero en consonancia con la práctica obsesiva de la autorreferencialidad paródica, recurrente en toda su obra a partir de la aparición de sus Poemas y antipoemas. A nuestro modo de ver, Juan Luis Martínez, desde la llamada neovanguardia chilena de las décadas del 70 y 80 , toma nota y sigue las huellas de ese legado para afiliarse de una forma más problemática y compleja, tal vez más subrepticia y sigilosa, a esa tendencia, optando por vías alternas regidas por estrategias constructivas propias de la posmodernidad.

Curiosamente, el parentesco entre estos tres poetas chilenos lo observan también, en el prólogo del libro Martínez Total (2016), Braulio Fernández Biggs y Marcelo Rioseco, pero en otro sentido, pues, para ellos, aunque Martínez "no le debe mucho a la misma tradición desde donde emergió" (13), su obra, junto con la de Huidobro y Parra, conforma una "tríada rupturista" notable en el campo chileno e hispanoamericano, como ilustración diáfana de la llamada tradición de la ruptura (13) propuesta por Octavio Paz. Esta tripleta, a su entender, posee además una cualidad muy particular: la de ser "perfectamente distribuida", al tomar en consideración las fechas de publicación de sus libros más relevantes. Es decir, ambos críticos constatan la presencia de un "triángulo perfecto" y "equilátero" compuesto por Altazor (1931) de Huidobro, Poemas y antipoemas(1954) de Parra y La nueva novela (1977) de Juan Luis Martínez, en el que "la diferencia entre la publicación de cada uno de los textos es, sorprendentemente, veintitrés años exactos” (13). En una nota de Diego Zúñiga, publicada en Letras libres el 12 de febrero de 2015, también se señala —en otro sentido, quizás menos geométrico- esta vinculación, al avalar episodios que certifican la importancia que tanto la obra de Huidobro como la de Parra tuvieron en la de Martínez. El cual, por cierto, a diferencia de estos dos, se caracterizó más bien por su escasa presencia pública y por su complacencia, como él mismo lo afirmó en una de las pocas entrevistas que dio, por "irradiar una identidad velada" (Lastra, "Sobre poetas" 25). Este aislamiento, que permitió en su momento clasificarlo como un poeta marginal, según la categorización propuesta por Pedro Lastra, se vio acentuado por varios factores, entre ellos: la enfermedad que lo aquejaba y que lo llevó relativamente temprano a la muerte; el ser un artista que fundamentalmente hizo su vida en la provincia y no en Santiago, el centro cultural del país, y las difíciles circunstancias políticas de la dictadura de Pinochet, que rigieron desde 1973 hasta las postrimerías de los años 80 y que limitaron los espacios de intercambio y promoción artística en Chile. No obstante, mediante diversos testimonios de gente cercana a su vida, ya se puede hablar de una narrativa que da cuenta de la existencia de un personaje "mítico" que inevitablemente resulta también implicada en la lectura de su obra. Según esa leyenda, Martínez fue un joven rebelde, hijo de un padre adinerado de Valparaíso que tenía entre otras aficiones la de "robar autos para luego despedazarlos echando carreras hacia Santiago con el acelerador a fondo" (Gavilán 21). Como producto de esas extravagancias, fue conocido como "el loco Martínez", y, bajo ese mote y esas prácticas, a los diecisiete años tuvo un accidente que lo dejó convaleciente por un buen tiempo. Según afirma Zúñiga, 
gracias a ello, y por intermedio de su madre, descubre la lectura y lee Altazor de Huidobro, a partir de lo cual, en palabras del periodista y escritor chileno: “Empieza todo". Por otra parte, en un testimonio de Fabián Cáceres, en esa misma nota, se nos dan noticias del encuentro que él tuvo con Juan Luis Martínez durante una visita que le hizo a principios de los noventa en la Villa Alemana. Allí, según asevera el poeta argentino, Martínez le confesó "sentado en una plaza bajo la sombra de un árbol, que Poemas y antipoemasno lo había dejado dormir". Es obvio que la obra de Martínez difiere en muchos aspectos de las de Huidobro y Parra, vale la pena, sin embargo, señalar algunos de sus parentescos, antes de caracterizarla más plenamente en su singularidad. De ambos libros, se rescata el ingenio y el artificio. Con Huidobro, Martínez comparte su concepción del arte como un ejercicio preminentemente intelectual, en el que tienen cabida las imágenes asombrosas y el absurdo, que dan lugar a versos como, en el caso del poeta de Altazor: "El vigor verdadero / reside en la cabeza" (391) o "Los cuatro puntos cardinales son tres: el Sur y el Norte" (732). Tal premisa se manifiesta de distintos modos en la obra de Martínez, pero siempre a través de un lenguaje visual o textual que produce, incluso al ser parodiado, un efecto de objetividad. Él mismo hizo explícita esta intención, al afirmar en una célebre conversación con Félix Guattari que, desde su perspectiva, "el gran problema artístico es la objetivización de la subjetividad”. El humor y el cultivo de la expresión gráfica, del cómic, del objeto visual en conjunción o no con la frase ingeniosa o el apotegma, tan propios de los variados "artefactos" parrianos, está sin duda muy presente en la tentativa de Martínez. Incluso, se podría afirmar que la aparición de ese libro de Nicanor Parra, cinco años antes de La nueva novela, de algún modo "naturalizó" en la tradición chilena la idea del poeta y la poesía ligados a ese tipo de expresión gráfica, ello sin tomar en cuenta la evidente abundancia de motivos tratados por Parra y reelaborados por Martínez, como lo chileno en sus múltiples aspectos y, en particular, en referencia con su bandera y su poesía; la alusión a lo europeo y lo norteamericano, en mucha mayor proporción que a lo latinoamericano; lo opuesto, lo contradictorio; la descalificación del sujeto lírico; la utilización burlesca de figuras históricas de la poesía, la política o la ciencia como Rimbaud, Marx o Einstein; el uso de operaciones aritméticas y silogismos; la puesta en duda del saber científico; la interpelación al lector mediante cuestionarios absurdos; la doble cara de las cosas; la lectura y escritura en espejo; la autorreferencialidad mediante la recurrencia a la inserción en el texto del propio nombre; la parodia del amor idealizado; la mención de la cosmología y la relatividad del tiempo y el espacio, entre otros. Ahora bien, en el caso de Martínez, su obra no va dirigida a la gente común, como aspiraba la obra de Parra, sino, por el contrario, vuelve al Olimpo, para el disfrute de unos pocos elegidos, no por tratarse de un lenguaje "privado", en el sentido de 'hermético' - asunto sobre el que hizo manifiesto su rechazo en la aludida conversación con Guattari-, sino por la elección de un decidido uso de objetos significantes (palabras, dibujos, fotos, esquemas, gráficos, etc.) que atentan contra la estabilidad de cualquier vínculo significativo, soportados sobre una compleja red de intertextos artísticos, culturales, filosóficos y científicos de difícil desentrañamiento para el lector común. Dicho esto, y a estas alturas, quizás deberíamos aclarar que sería una impropiedad calificar de antipoeta a Martínez o de antipoesía su obra. Muchos, incluso, han subordinado su virtual condición de vate a la de artista visual y/o conceptual, por apreciar en las especificidades de su trabajo mayores cercanías con tales tipos de propuestas artísticas. Por otra parte, ciertamente, son muy pocos los poemas que podríamos calificar como tales, de acuerdo con los parámetros genéricos tradicionales, en la totalidad de su obra, si dejamos de lado los que conforman su libro póstumo Los poemas del otro, de los cuales 17 son traducciones del francés al español de poemas "líricos" de un poeta suizo-catalán que también se llama Juan Luis Martinez (sin acento), y que el chileno hizo pasar por suyos al publicar y leer algunos de ellos en vida. Habría que precisar, no obstante, que, al hacerlos pasar por suyos, lo hizo oblicuamente - para usar un adverbio predilecto del poeta venezolano Eugenio Montejo (1938) - , pues en diversas oportunidades admitió o advirtió que no habían sido escritos por él, sino por "el otro", lo cual siempre fue interpretado como parte de su prédica de anulación del yo y de su cuestionamiento de la función autorial. Un año antes de su muerte, leyó además en París, en 1992, ante una importante audiencia, uno de esos poemas, llamado "Qui je suis", hecho que hace evidente la importancia y funcionalidad que la aparición de ese "otro" tendría potencialmente en su proyecto artístico, más allá de si en 
efecto aprobaría o no la publicación póstuma del libro los Poemas del otro. Es de este modo, y aun en vida, que el autor de "Identidad velada" surgido con La nueva novela comienza a darle cabida, sigilosamente, a ese "otro", y que comienza a tomar forma el desdoblamiento entre los dos Martínez: el de los poemas antilíricos y el cultor de una estética contrapuesta. De alguna manera, la imagen aludida en la célebre frase de Lautreamont ("Un encuentro fortuito de una máquina de coser y un paraguas en una mesa de disección”) calza perfectamente con la naturaleza de la aparición de ese "otro" en la obra del Martínez chileno, lo que le permitió no solo parodiar implícitamente la creación heteronímica, sino verificar en los hechos la eficacia del azar objetivo y la irrelevancia de las fronteras entre ficción y realidad. Este descubrimiento fue hecho recientemente, en 2013, por el investigador norteamericano Scott Weintraub, quien, en su libro La última broma de Juan Luis Martínez, recoge las peripecias de su labor detectivesca y la naturaleza de sus hallazgos. Con esta llamémosla entonces "broma”, Martínez lleva al límite su intento de cuestionar toda convención autorial, haciendo válidas sus palabras cuando afirma, yendo un paso más allá en las aspiraciones que también se planteó Borges, que

mi mayor interés es la disolución absoluta de la autoría, la anonimia, y lo ideal, si se puede usar esa palabra, es hacer un trabajo, una obra, en la que no me pertenezca casi ninguna línea, articulando en un trabajo muchos fragmentos, pedacitos que se conectan. Es un trabajo de Penélope. (Guattari)

No parece entonces impertinente pensar la estrategia compositiva de esta obra en términos de una "máquina de coser" a la caza de encuentros fortuitos.

\section{Borgiano y antiborgiano: la identidad velada o la tachadura que subraya}

Ahora bien, curiosamente, lo borgiano en Martínez pareciera adquirir su mayor concreción, su mayor realidad - si cabe el término- dentro de su universo de trampas y juegos ilusorios, en situaciones de orden extraliterario vinculadas más con la existencia virtual y los enmascaramientos de esa "identidad velada", hecha mito, que, estrictamente, con la naturaleza de su obra. Dos circunstancias llamativas lo corroboran. La primera ocurrió en noviembre de 1988, cuando el periodista Luis Vargas Saavedra en una página del diario ElMercurio, en la que reseñó el ensayo "Señales de ruta de Juan Luis Martínez", publicado el año anterior, sugirió que posiblemente ese no era más que una invención de Lihn y Lastra, afirmando que "acaso Juan Luis Martínez ni siquiera exista" (Lastra, "Sobre poetas" 25). La otra, ocurrida en tiempos más recientes, en el 2014, luego del hallazgo de Weintraub, la encontramos en un texto escrito por Juan (Luis) Martinez (sin acento); es decir, el otro, el que aún lo sobrevive, el autor del libro El silencio y su ruptura, a quien Martínez nunca conoció. Este poeta suizo-catalán, tras conocer la "broma”, reflexiona sobre las causas que llevaron al poeta chileno a lo que él califica como una "especie de suicidio literario" (Martinez 353); tal vez, Martínez estuvo impulsado más por el deseo de dar cumplimiento a su oficio como "dramaturgo de su vida poética" (recordemos que Guillermo Sucre habla de la "teatralidad del yo" como una característica intrínseca de la relación entre la poesía y el poeta en una zona de la tradición poética chilena, tal como lo referimos al comienzo de estas páginas) y no tanto por querer "desaparecer como autor, como él lo pretendía", sino por querer "desafiarla noción de autor, transformarla a través de préstamos conscientes a otros artistas, como ya era costumbre en la disciplina de las artes plásticas" (Martinez 355). Tales circunstancias nos obligarían, por otra parte, a considerar la lectura en clave paródica de ciertos elementos paratextuales de esta obra, en vista de lo señalado y de la naturaleza de este proyecto artístico. Incluso, dejando de lado las obras póstumas, cómo interpretar cabalmente en $L a$ nueva novela, por ejemplo, el texto que se encuentra bajo el copyright, en el que se certifican los derechos de autor inscritos bajo el n. 45323 de la edición facsimilar de 1985, y que reza así: "La reproducción total o parcial de este libro en forma idéntica o modificada, escrita a máquina o reproducida por el sistema multilith, mimeógrafo, impreso, fotocopia, etc., no autorizada por el autor, viola sus derechos. Cualquier utilización debe ser previamente solicitada”. Inevitablemente nos asalta la pregunta: ¿`será la exacerbación de una broma, 
otra forma de teatralización de la función autorial o simplemente una convencional y muy seria advertencia editorial sobre el respeto que se debe guardar de los derechos de autor?

A este respecto, más allá del insólito paradero borgiano al que ha llevado el destino a esta obra, causado en parte por la común fascinación por el desdibujamiento autorial, pareciera necesario advertir que, en efecto, desde sus inicios, la búsqueda artística de Martínez estuvo acompañada por el deseo de darle expresión a las "ideas provenientes de reflexiones de críticos deseosos de explorar nuevos continentes, de descifrar nuevos códigos" (Martinez 359), como lo afirmó el otro Martinez, al referirse a La nueva novela; obra que a su entender contenía “( $t$ )oda la sustancia de lo que [Martínez] tenía que decir” (Martinez 358-359). Este libro-objeto tuvo además como antecedente una exposición titulada, precisamente, "Objetos", compuesta de collages y objetos visuales, la cual se realizó en el Instituto Chileno-Francés de Valparaíso, en 1972. Ese mismo año, también aparecieron los únicos seis poemas publicados por Martínez hasta esa fecha, en una antología aparecida en Argentina y preparada por Martín Micharvegas, llamada Nueva poesía joven de Chile. De esos seis textos, cinco fueron incluidos — con algunas variaciones - en La nueva novela (Gavilán 25-26).

Después de todo lo dicho hasta aquí, tal vez sería válido hacer uso de la respuesta que dio Cortázar a la pregunta de si podría considerarse Rayuelacomo una antinovela (el escritor argentino respondió que, en todo caso, optaría por llamarla una contranovela). Consecuentemente, podríamos calificar a Martínez como un contrapoeta y a su obra como contrapoesía, pues, más que oponerse, lo que busca es poner en crisis, cuestionar las nociones imperantes que condicionan los acuerdos de producción y recepción que determinan su calificación en los términos convenidos desde la modernidad. ¿No hay acaso en el nombre mismo de su libro-objeto, La nueva novela, un acto de provocación en esa dirección? ¿No hay en ese acto una incitación, una invitación a pensar dicha obra como un compendio de tramas complejas y paradójicas en constantes cruzamientos? Una vez ponderadas las anteriores consideraciones, la intención rupturista de la obra de Martínez podríamos entenderla desde dicha premisa, del mismo modo que lo hicimos respecto al creacionismo huidobriano y la antipoesía parriana. Uno de los cuestionamientos que marcan precisamente su ruptura con la tradición poética que lo precede está justamente asociado con la noción de sujeto como una unidad estable dentro del texto, así como también la de autoría. Sobre ello, en esa misma conversación con Guattari afirmó: "Pienso que el arte que proviene en general del romanticismo alemán, del surrealismo está terminado porque el sujeto está terminado. Las identidades tan nítidas —usted, Félix Guattari, yo, Juan Luis Martínez- están terminadas, en cuanto al arte”.

En resumen, podríamos compendiar algunas de las características de la obra de Martínez al considerarla como una obra en la que el autor predica su anulación, tachando su nombre, para, desde esa tachadura, hacer manifiesta su continua ausencia-presencia, siempre cuestionada y cuestionadora, que, además de poner en tela de juicio categorías como la de obra y autoría, impugna nociones como las del yo y el tú, el ser y el no-ser, el espacio y el tiempo, la realidad y la idealidad, entre otras, mediante una puesta en escena sumamente imaginativa en la que se diluyen las fronteras entre formas genéricas y modalidades de saberes. Su apuesta estética se vale del acopio, de la acumulación y de la articulación de materiales de diversa índole puestos al servicio de la elaboración de un artefacto conceptual y artístico, en el que se conjugan variadas formas de lenguaje, figuras de pensamiento y estrategias retóricas, con una clara vocación rupturista y confrontacional que "ingeniosamente" se reapropia de códigos y postulados de la modernidad, resignificándolos de múltiples modos, con el propósito de inscribirse en los debates intelectuales, filosóficos, científicos y artísticos contemporáneos de Occidente, sin dejar de lado su actuación como un signo disruptivo en el campo local, es decir, en el propio campo literario chileno, especialmente pugnaz y beligerante, y dentro del ámbito general de la poesía latinoamericana. No obstante, calificar esta tentativa de meramente literaria o poética sería impreciso y limitante, pues se trata de una obra que desborda cualquier clasificación genérica convencional, configurándose más bien como un dispositivo artístico y conceptual, un complejo sistema elusivo y alusivo, reflexivo y estético, de alta potencia significante, confeccionada a partir de la alianza entre la imagen, la palabra y el signo numérico, y mediante variados modos de apropiación e intertextualidad, 
enlazados por el juego, el humor, el absurdo, la alegoría, la analogía, la contraposición, el silogismo o la paradoja.

A todo esto, quisiéramos asomar una breve reflexión sobre ciertas características de esa "identidad velada" expuesta en la obra martiniana que, como hemos dicho, a nuestro modo de ver se construye desde estrategias propias de la posmodernidad, que quieren distanciarse de la tradición precedente. En su caso, se pone en entredicho la función textual de la autoría, pero no acudiendo a seudónimos o al simple ejercicio del anonimato. Martínez decide optar, ante todo, por la tachadura de su nombre, pero no usa una tachadura que cancela toda posibilidad de revelación de lo suprimido, sino, por el contrario, usa una que parece atender más bien a una necesidad de simulacro, una tachadura que, en lugar de ocultar, hace más patente y notorio, más visible, el nombre marcado, parcial o imperfectamente duplicado: "Juan Luis Martínez" y "Juan de Dios Martínez", el cual aparece en la página inicial de La nueva novela, junto con los datos editoriales y el perro SOGOL - anagrama de LOGOS, como lo descubriremos en la lectura-, encerrado en un círculo. Su nombre, tachado o no, con una " $x$ " intercalada o mediante alusiones oblicuas (como en un poema dedicado a sus padres, Isabel Holguier Dabadie y Luis Martínez Villablanca, titulado "La casa del aliento, casi la pequeña casa del (autor)", por ejemplo), lo encontramos cinco veces más en La nueva novela, distribuido en distintos espacios y con distintas funciones semánticas a lo largo de la estructura del libro en las páginas 70, 77, 87, 90 y 91. En La poesía chilena, publicada al año siguiente, en 1978, nos encontramos con el mismo procedimiento (la doble tachadura de los dos nombres que son y no son el mismo) debajo del título. Como es obvio, a pesar de su "identidad velada", Martínez, tachándose doblemente, busca instalarse en la escena literaria de su país (acudiendo además al recurso de la bandera patria en ambas obras) no desde el cultivo de una egolatría abierta, sino desde las hendiduras de una escritura que, dice, quiere ser borrada para seguir presente, desde el trazo o la tachadura, fiel a ciertas concepciones posestructuralistas, cuya pertinencia en la obra de Martínez, además de intrínseca, es claramente explícita. En La nueva novela encontramos páginas en las que se habla de lecciones "no logocéntricas" (79) o de "la grafología"(91); otras en las que se cita a Saussure y se hace mención de las dos caras de la hoja de papel y la relación entre el pensamiento y el sonido (100); otras en las que tácitamente se alude a la noción del devenir, de Deleuze y Guattari (112), y se afirma que "una burbuja en pleno camino hacia la pared de la taza, será una burbuja-café" y que "una burbuja pegada a la pared de la taza, será una burbuja-pared"; otras conformadas por dibujos de distintos tipos de llaveros, titulada "Nota 4. FOX TERRIER NO DESAPARECIDO EN LA NO INTERSECCION DE LAS NO AVENIDAS (GAUSS LOBATCHEWSKY)", en las que se hace alusión al virtual punto de intersección de planos representados desde la geometría euclidiana y no euclidiana, y en la que el logos, de acuerdo con el punto desde el que se le mire, se haría visible o invisible, y otras en la que se hace referencia a Derrida, al hablar de la "Deconstrucción del logos" (124), de nuevo a Guattari y su La transversalité (125) o al mismo Martínez, a través de una reiteración más de su nombre, esta vez acompañado del número 1977, seguramente haciendo referencia al año de publicación de su libro.

Todos estos elementos, entre muchos otros abundantes en su apuesta artística, han hecho que buena parte de la crítica lo haya calificado como un poeta del significante, aunque esto tendríamos que asumirlo desde una perspectiva muy ajena a lo que por ello se entendería desde otros tipos de búsquedas, como, por ejemplo, el neobarroco de Lezama o de Sarduy (quien veía un proceso histórico paralelo entre las sucesivas concepciones del cosmos, desde el geocentrismo hasta el Big bang, y el estallido progresivo del signo lingüístico) o de la amplia gama de escritores y poetas atraídos por esa práctica estética a lo largo y ancho de América Latina. Tampoco se trataría de una modalidad de las jitanjáforas de Mariano Brull (1891-1956), ni del gíglico cortazariano o de la llamada poesía del lenguaje, o de tantas otras tentativas con fines similares. El significante, en el caso de Martínez, es el constituyente fundamental del poema (deslastrado de todo posible vínculo con un pretendido significado). El poema al que se aspira como postulado de La nueva novela, según se afirma en una nota en la página 30, es aquel que pone de manifiesto 
su más exacta e inmediata textualidad (sin distancia ni traducción): un poema absolutamente plano, texto sin otro significado que el de su propia superficie. El dibujo de las letras, el cuerpo físico de sus palabras, el espesor de los signos desnudos que traspasando el delgado espesor de la página emergen [...] en mera escritura, destruyen cualquier intento de interpretación respecto a una supuesta: 'Profundidad de la literatura'.

Esta afirmación aleja claramente la tentativa de Martínez, ampliando lo dicho con anterioridad sobre la poética borgiana, con la que tanto se le ha relacionado, pues para Martínez en la literatura no habría significado posible, no habría cifra, ni revelación, ni cábala, ni metafísica (de la cual se mofa paródicamente en la página 31), solo superficie, materialidad y sonido, desentendidos de toda intención hermenéutica.

Así, lo que encontramos en Martínez con relación a Borges es de nuevo un juego de afinidades y oposiciones: un Martínez borgiano y uno antiborgiano. En una cara, se afilia con uno que predica la supremacía del lector, que entiende como irrelevante toda autoría y acude profusamente al uso de citas apócrifas, que hace de los libros una experiencia lúdica ante un objeto cambiante, enigmático y evasivo basta recordar el cuento "El libro de arena" de Borges o las páginas de La nueva novela en las que se guía al lector o se lo interroga, para apurarlo o para informarle que ha llegado tarde o que tiene que desplazarse a otra página, o para pedirle que haga cálculos con respecto a la velocidad y el tiempo en que acontecen las cosas en el libro-; y, en la cara contraria, se afilia con otro al que se opone, que ve en la literatura una expresión de la metafísica (la cual incluso entiende como "una rama de la literatura fantástica"), de la búsqueda del sentido secreto de la existencia y una clave para comprender las razones del universo y el nombre de Dios. Uno en el que la literatura, sin duda, supone gravedad y profundidad.

\section{Entre binarismos, paradojas y alados significantes}

Similares dinámicas podemos encontrar en los diversos núcleos binomiales que conforman La nueva novela, entre ellos, por ejemplo, el que se refiere a las formas de pensamiento occidental y oriental, las cuales, paradójicamente, si por una parte se complementan, por otra se oponen de modo irreconciliable. Toda la obra de Martínez se construye desde una oposición binaria: la presencia-ausencia, la versión positiva y negativa del mundo y su representación, la inestabilidad de todo lo que alternativamente se hace visible e invisible. Así, junto al logos y el ideal están el sogol y un personaje llamado Delia (como anagramas y opuestos complementarios que activan esa presencia-ausencia de contrarios). Del mismo modo, al saber occidental representado, precisamente, por el logos, se le opone el oriental, encauzado desde el tao. Esto lo expresa claramente en una nota (página 96) de un texto titulado "Silogismo homenaje a René Crevel 'el más buenmozo de los surrealistas", en el que afirma: "Tao significa propiamente camino. Primitivamente esta palabra se usó para designar el curso de las estrellas en el cielo. Es el concepto fundamental de la filosofía china y su equivalente al logos griego, y, sin embargo, fundamentalmente distinto". En realidad, podríamos afirmar que esta incesante dialéctica entre equivalencias que a la vez se oponen es uno de los rasgos estructurales de toda la obra de Martínez. El asedio del "Demonio de la Analogía", como se dice en un verso del poema de obvio corte Mallarmeano, "El cisne troquelado" y la constante tendencia a polarizar, en versiones positivas y negativas, las formas de representación y comprensión de la realidad, del lenguaje, del mundo y en última instancia del mismo libro son consustanciales a la propuesta artística de Martínez. Así, encontramos que referencias al Tao y luego al I Ching se despliegan en la totalidad de la obra de Martínez, más allá de La nueva novela, en una aparente oposición complementaria, pero efectivamente en una insinuada analogía, con otras teorías del campo científico en el ámbito occidental, como la teoría de la relatividad, la geometría no euclidiana o el principio de incertidumbre, en el que las nociones de realidad, absoluto, determinismo, estabilidad o presencia.ausencia también son impugnadas. Es decir, paradójicamente, Martínez encuentra los equivalentes del Tao y del I Ching no en el logos occidental, sino en teorías físicas surgidas en el siglo XX y en la geometría desarrollada a comienzos del siglo XIX por Gauss y Lobachevski, todas ellas hijas de ese cuestionado logos. 
Consecuente con este procedimiento —el de la identificación de pares a la vez opuestos y afines-, la obra de Martínez, desde el marco de la lógica paradójica, autogenera sistemáticamente sus propias contradicciones: esa es la naturaleza de las tramas que produce. Si la preminencia del significante rige el norte de su búsqueda artística, tal como lo afirma al decir "a mí en realidad no me importa escribir bien o mal; lo que me importa es dar cuenta de mis intuiciones, pero todo esto siempre y cuando el significante prime el significado" (Guattari), esto mismo, tal vez, es lo que le lleva a afirmar en la página siguiente a la de la nota sobre el Tao y el logos, al pie de un texto titulado "La poesía china", que "fundamentalmente [y notemos el uso repetido de este adverbio] la poesía china, (en su forma actual o en otra cualquiera) no ha existido jamás" (97). ¿Qué sentido tiene esta afirmación?, podríamos suponer que no se trata más que de un nuevo guiño al absurdo, una nueva burla. Sin embargo, en un esfuerzo de comprensión, si aceptáramos el juego y cayéramos en la tentación de intentar alguna explicación coherente — una vez sabido que la lámina que se superpone a la página 97 , donde al pie se encuentra la nota señalada, está conformada por un conjunto de caracteres que, según la investigación recientemente hecha por Marcelo Rioseco (269-280), corresponde a "una página cualquiera de un diccionario en chino" y a nada más-, quizás podríamos convenir que esta aseveración aparentemente disparatada se sustenta, precisamente, en el hecho de que el idioma en el que fue escrito el Tao, desde el cual se ha cultivado profusa y extensamente el pensamiento paradójico, representado por una página cualquiera de un diccionario chino, es una lengua basada en ideogramas, no fonética, lo cual imposibilita la primacía del significante y el sonido sobre la idea. Por eso, al leer lo que oculta la lámina con caracteres chinos del diccionario, superpuesta a la página en cuestión, encontramos dos poemas, uno atribuido a Shen-hsiu ("El cuerpo es el árbol Bodhi / La mente el espejo brillante en que él se mira / Cuidar que esté siempre limpio / Y que polvo alguno lo empañe" [97]) y otro a Hui-neng ("Nunca existió el árbol Bodhi / Ni el brillante espejo en que él se mira / Fundamentalmente nada existe / Entonces, ¿qué polvo lo empañaría?" [97]) que se oponen semánticamente mediante dos postulados: uno que concibe la conciencia como un instrumento perceptivo del yo y de la realidad, y otro que la concibe como el mero resultado de la proyección ilusoria de aquélla. A continuación, de estos poemas hay dos notas adicionales (ubicadas y por ello también ocultas debajo de la lámina), pero que anteceden y complementan la nota señalada anteriormente referida a la inexistencia de la poesía china, que afirman: "Nadie leerá nunca / oirá (interpretará mentalmente) estos dos poemas chinos" y "Nadie recordará nunca / tarareará (evocará mentalmente) estos dos poemas chinos" (97). Dicho en otras palabras, no puede haber poesía, entendida en los términos postulados en La nueva novela en una lengua que más que oírse o tararearse se piensa, una lengua cuyos caracteres nos remiten necesariamente a una idea, es decir, paradójicamente al logos, no a una "confabulación fonética" — como desearía一, sino al signo cargado de sentido, al concepto. De allí que sea la página de un diccionario de esa lengua ideográfica la que impida, ocultando los poemas, escucharlos antes que pensarlos.

En conclusión, entendida la tarea de Juan Luis Martínez como la de un constructor de artefactos artísticos, resulta evidente su filiación con las prácticas receptivas de los ready made, del arte conceptual e, incluso, de la idea de obra de literatura potencial que acuñó la agrupación experimental OuLiPo en Francia. De hecho, según los postulados que se desprenderían de lo que concibe como arte y poesía, ninguno de sus poemas, por lo demás la mayoría de ellos extraordinarios, podrían calzar dentro del objetivo estético implicado en su planteamiento, pues ellos constituirían la enunciación de un propósito, no su realización, la cual supondría, por cierto, la ininteligibilidad, la mera actuación de una lengua adánica, "la lengua de los pájaros", como la imagina Benjamin y la refería Agamben, una en la que "la palabra no comunica nada sino a sí misma” (Agamben 43). En ninguno de los poemas de Martínez el significante alcanzaría la independencia deseada para atender esos fines, pues son poemas umbrales que llegan al límite para anunciar el siguiente paso, conscientes de la imposibilidad de darlo, pues somos humanos, demasiado humanos, y la palabra necesariamente nos condena a la vigilancia de un orden semántico. De este modo, así como los poetas místicos, paradójicamente, en tanto poetas aspiran al silencio desde la palabra, también será desde allí que Martínez postulará el pajaristico como la lengua propia de la poesía, aquella en la que los significantes 
dancen libres de ataduras. Ese "lenguaje de signos transparentes / en busca de la transparencia dispersa de algún significado" ("Observaciones relacionadas con la exuberante actividad de la 'confabulación fonética' o 'lenguaje de los pájaros’ en las obras de J. P. Brisset, R. Roussel, M. Duchamp y otros”) (89).

\title{
Un último encuentro a partir de Nada
}

Hace un tiempo, en una conversación aparentemente ocasional, pero en realidad propiciada por mí, Pedro Lastra recordaba el día en el que conoció a Juan Luis Martínez, en 1971. Según me dijo, desde el primer momento lo cautivó su simpatía. Vio en él a una persona amable y discreta, poco propenso al cultivo de la egolatría. Este llevaba el manuscrito de un libro inclasificable, que para entonces se titulaba Pequeña cosmogonía práctica. Es decir, un libro objeto que luego se transformaría en La nueva novela. Curiosamente, en la versión de 1977 y de 1985, en la página 34, bajo ese título de "Pequeña cosmogonía práctica" se plantea el siguiente problema: "Construya un mundo coherente a partir de NADA, sabiendo que YO = TÚ y que todo es posible". A continuación, se señala entre paréntesis: "Haga un dibujo". El tema es recurrente en Martínez: la proyección del yo en lo otro (en el tú) como única alternativa para crear la ilusión (la idea) de lo REAL, en oposición a la NADA. Lo significativo, me parece, es que la primera respuesta es escrita y sugiere la posibilidad de la muerte, y, eventualmente, del suicidio, como solución al problema planteado ante la incapacidad para alcanzar el tú deseado. La segunda respuesta, exclusivamente gráfica, titulada precisamente "La nueva novela", ofrece como única alternativa la destrucción de ese tú (de ese ideal proyectado). Tal vez, esa página contenga alguna de las claves para especular sobre el sentido y tipo de mutaciones que el libro, originalmente entregado a Lastra como asesor de la Editorial Universitaria y director de la Colección Letras de América, sufrió en el tiempo. Tal vez, el aspecto gráfico del libro fue adquiriendo mayor relevancia en su largo proceso de construcción. Nunca lo sabremos, pues ese manuscrito desapareció, como tantas personas y cosas desaparecieron en Chile, bajo la implacable dictadura que la rigió entre 1973 y 1990. El libro, infelizmente, no se pudo publicar en ese momento, dadas esas difíciles circunstancias, a pesar de haber sido aprobada su edición. Lastra recordaría esa tarde, también, algo ocurrido años después. El momento en el que Martínez, con ocasión de una visita del autor de "Noticias del extranjero" a su casa, le mostró la carta firmada por él, en la que se le notificaba que su libro había sido aprobado para ser publicado. Martínez enfatizó, con emoción y gratitud, lo importante que había sido esa carta en su vida. Años después, en 1977, durante un invierno - ya para entonces Lastra venía poco a Santiago, pues era profesor en la Universidad del Estado de Nueva York, en Estados Unidos, y se había ausentado unos años de Chile-, según me contó, una tarde estaba parado en la calle Compañía y de pronto Juan Luis Martínez, ese ser de “identidad velada”, apareció a su lado y le mostró la edición de La nueva novela, publicada por él mismo, ese año, en Ediciones Archivo. Luego de reconocerse y saludarse con alegría, le escribió una dedicatoria que reza algo así: "Para mi amigo Pedro Lastra, mi primer lector".

En estos días, mientras me seguía rondando en la cabeza el caso Martínez, soñé que Pedro Lastra me hablaba de un poema escrito por el autor de La nueva novela y que le había enviado desde el más allá, tal vez desde la intersección de las avenidas Gauss y Lobatchewski, un poema escrito en pajarístico, por lo tanto, difícil de entender, pero que comenzaba con una estrofa que se reiteraba a lo largo del poema, escrita en español, esa lengua opaca. Esa estrofa dice así, y así concluyen estos tramados apuntes:

\author{
Nada de lo que se diga aqui \\ Saldrá de nosotros \\ Porque nada es igual a Nada \\ $Y$ Nada tiene sentido. \\ Ese es su único sentido.
}




\section{Referencias}

Agamben, Giorgio. La potencia del pensamiento. Anagrama, 2008.

Fernández Biggs, Braulio y Marcelo Rioseco, editores. "Prólogo". Martínez Total. Editorial Universitaria, 2016, pp. 11-15.

Gavilán, Ismael. “Juan Luis Martínez: fragmentos para una biografía infructuosa”. Martínez Total, editado por Braulio Fernández Biggs y Marcelo Rioseco, Editorial Universitaria, 2016, pp. 19-31.

Guattari, Félix. "Conversación con Juan Luis Martínez". Letras.s5.com, http://www.letras.mysite.com/jlmartinez230 801.htm.

Huidobro, Vicente. Obra poética de Vicente Huidobro. Colección Archivos, 2003.

Ioannis, Antzus Ramos. “Guillermo Sucre. Diálogos a la distancia”. Trópico absoluto, https://tropicoabsoluto.com/?p $=517$.

Lastra, Pedro. "Sobre poetas marginales". Mapocho. Revista de Humanidades y Ciencias Sociales, n. . 43, 1998, pp. 1-27.

Lastra, Pedro y Enrique Lihn. Señales de ruta de Juan Luis Martínez. Ediciones Archivo, 1987.

Martinez, Juan (Luis). "El sueño del espejo vacío”. Martínez Total, editado por Braulio Fernández Biggs y Marcelo Rioseco, Editorial Universitaria, 2016, pp. 353-361.

Martínez, Juan Luis. La nueva novela. Ediciones Archivo, 1977.

Micharvegas, Martín. Nueva poesía joven de Chile. Noé, 1972.

Parra, Nicanor. Poemas para combatir la calvicie. Fondo de Cultura Económica, 1993.

Rioseco, Marcelo. "Juan Luis Martínez y las intertextualidades orientales. El caso de la página en chino y los trigramas del I Ching". Martínez Total, editado por Braulio Fernández Biggs y Marcelo Rioseco, Editorial Universitaria, 2016, pp. 269-294.

Weintraub, Scott. La última broma de Juan Luis Martinez: no solo ser otros sino escribir la obra de otro. Editorial Cuarto Propio, 2014.

Zúñiga, Diego. "Juan Luis Martínez". Letras libres, https://www.letraslibres.com/mexico/juan-luis-martinez. Consultado el 12 de febrero de 2015.

\section{Notas}

* Artículo de reflexión. Este artículo es una versión de la conferencia de apertura del Simposio Internacional "Juan Luis Martínez: análisis, diálogos y relecturas", dictada el 5 de junio de 2019 en la Universidad de los Andes, Santiago de Chile.

\section{Licencia Creative Commons CC BY 4.0}

Cómo citar este artículo: Gutiérrez Plaza, Arturo. “Tramas cruzadas en el extraño caso de Juan Luis Martínez”. Cuadernos de Literatura, vol. 25, 2021. https://doi.org/10.11144/Javeriana.cl25.tcec 